\title{
PRODUÇÃO E PURIFICAÇÃO DE ANTICORPOS POLICLONAIS IgY ESPECÍFICOS PARA LEISHMANIA AMAZONENSIS
}

\author{
PRODUCTION AND PURIFICATION OF POLYCLONAL IgY ANTIBODIES \\ SPECIFIC TO LEISHMANIA AMAZONENSIS
}

\author{
L. F. V. BLANCO ${ }^{1}$, R. P. RIBEIRO ${ }^{1}$, J. E. MENEGHINI ${ }^{1}$, M. MATEUS ${ }^{1}$, M. A. SANTOS $^{2}$, \\ T. L. TEIXEIRA ${ }^{2}$, J. P. SANTOS ${ }^{1}$, C. V. SILVA ${ }^{2}$, A. FERREIRA JUNIOR ${ }^{2 *}$
}

\section{RESUMO}

Os objetivos foram: (i) produzir anticorpos policlonais IgY contra o antígeno total de promastigotas (ATPro) de Leishmania amazonensis; (ii) purificar anticorpos da gema do ovo de galinhas imunizadas; (iii) avaliar a qualidade da purificação; e (iv) diagnosticar as alterações macroscópicas pós-imunização. Três galinhas da linhagem HiSex foram imunizadas com $100 \mu \mathrm{g}$ de ATPro/250 $\mu \mathrm{L}$ de PBS (pH 7,2) emulsionado em $250 \mu \mathrm{L}$ de adjuvante completo (imunização primária) e incompleto ( $2^{\circ}$ e $3^{\circ}$ booster) de Freund, pela via intramuscular e com intervalo de 14 dias. O volume final $(500 \mu \mathrm{L})$ foi inoculado em quatro locais do músculo peitoral. Os ovos foram colhidos diariamente e as gemas foram armazenadas a $20^{\circ} \mathrm{C}$. A fração solúvel em água (FSA) foi obtida da gema total, por meio de precipitação em água acidificada (pH 5,0-5,2), seguida de salting-out da FSA com sulfato de sódio (19\% e 14\%). A purificação foi avaliada por meio de eletroforese em gel de poliacrilamida (SDS-PAGE) $12 \%$ e pelo teste de dot-blot com anticorpos anti-IgY. O diagnóstico das alterações macroscópicas foi realizado durante a necropsia das aves imunizadas, por inspeção do músculo peitoral. Obteve-se um sobrenadante translúcido (FSA) e um precipitado denso de cor amarela. O salting-out da FSA resultou em um precipitado de cor branca (PY). O SDS-PAGE demonstrou a progressiva remoção de contaminantes, a cada etapa da purificação. A fração PY apresentou uma banda proteica de peso molecular estimado de $180 \mathrm{kDa}$, além disso detectou-se a presença dos anticorpos IgY nesta fração. No músculo peitoral, diagnosticaram-se estruturas encapsuladas drenando, ao corte, líquido amarelado e viscoso. Utilizando metodologia de fácil execução, é produzida uma fração enriquecida em anticorpos IgY com grande potencial de emprego nos estudos celulares para a compreensão da interação de L. amanzonensis e as células hospedeiras. Adjuvantes de Freund produzem, em galinhas, lesões inflamatórias extensas nos locais das imunizações.

\section{PALAVRAS-CHAVE: IMUNOGLOBULINAS. TRIPANOSSOMATÍDEOS. PROTEÔMICA.} PATOLOGIA.

AGRADECIMENTO: CNPq e Instituto de Estudos Avançados em Medicina Veterinária José Caetano Borges.

ÁREA TEMÁTICA: Doenças Parasitárias

\footnotetext{
${ }^{1}$ Universidade de Uberaba. Programa de Mestrado em Sanidade e Produção Animal nos Trópicos. Instituto de Estudos Avançados José Caetano Borges. Campus Aeroporto.* alvaro.junior@uniube.br

${ }^{2}$ Universidade Federal de Uberlândia. Laboratório de Tripanossomatídeos. Instituto de Ciências Biomédicas. Campus Umuarama.
} 